\title{
Analysis of speckle patterns in electronic devices for the monitoring of current changes
}

\section{Análisis de patrones de speckle en dispositivos electrónicos para el monitoreo de cambios de corriente}

\author{
LÓPEZ-ÁLVAREZ, Yadira Fabiola†*1,2, JARA-RUÍZ, Ricardo ${ }^{1}$, RODRÍGUEZ-FRANCO, Martín \\ Eduardo $^{1}$, and DELGADO-GUERRERO, Sergio Humberto ${ }^{1}$ \\ ${ }^{1}$ Universidad Tecnológica del Norte de Aguascalientes, Aguascalientes, Estación Rincón, Rincón de Romos, Aguascalientes, \\ 20400 México \\ ${ }^{2}$ Universidad de Guadalajara, Lagos de Moreno, Jalisco, 47460, México
}

ID $1^{\text {st }}$ Author: Yadira Fabiola, López-Álvarez / ORC ID: 0000-0002-9041-1908, Researcher ID Thomson: T-1555-2018, CVU CONACYT ID: 375952

ID $1^{\text {st }}$ Coauthor: Ricardo, Jara-Ruiz / ORC ID: 0000-0001-7725-4138, Researcher ID Thomson: T-1532-2018, CVU CONACYT ID: 630276

ID $2^{\text {nd }}$ Coauthor: Martín Eduardo, Rodriguez-Franco / ORC ID: 0000-0002-6804-4777, Researcher ID Thomson: T-15392018, CVU CONACYT ID: 660892

ID $3^{\text {rd }}$ Coauthor: Sergio, Delgado-Guerrero / ORC ID: 0000-0003-2521-5887, Researcher ID Thomson: V-1747-2018, CVU CONACYT ID: 240475

DOI: $10.35429 /$ EJT.2021.9.5.1.7

Received March 20, 2021; Accepted June 30, 2021

Abstract

Derived from new advances technological focused on the development of highly functional electronic devices; the manufacturers are obliged to the implementation of techniques to monitor their behavior. These techniques can be destructive or non-destructive, taking the analyzed device to the maximum working range. In this investigation report we show of the results obtained in the study of the speckle patterns of a positive voltage regulator, we used the probability density function and the correlation coefficients, as a statistical analysis of first and second order. The analysis was realized in each terminal of the electronic device, with changes in the input current. The result obtained suggest that the first and second order statistical analysis are good tool in a not destructive measurement and that its results can be relationship with the supply current. These changes are present a behavior ascending as the device operates in the junction temperature range; presenting itself as a mechanism for transmission and convection of heat, using the random distribution of speckle pattern, taking to optical measurement as an technique alternative in the study of electronic devices.

Speckle pattern, Probability density function, Correlation coefficients

\begin{abstract}
Resumen
Derivado de los nuevos avances tecnológicos enfocados en el desarrollo de dispositivos electrónicos altamente funcionales, los fabricantes se ven obligados a la implementación de técnicas para el monitoreo del funcionamiento de cada dispositivo electrónico, estas técnicas pueden ser destructivas o no destructivas, llevando al máximo rango de trabajo al dispositivo analizado. En este trabajo se reportan los resultados obtenidos en el estudio de los patrones de moteado (speckle) de un regulador de tensión positiva, mediante el análisis del comportamiento de la función de la densidad de probabilidad y de los coeficientes de correlación. Los resultados obtenidos sugieren que el comportamiento de la función de densidad de probabilidad de los patrones de speckle y los coeficientes de correlación de cada terminal del regulador de voltaje muestran una relación directa con los valores de la corriente de alimentación, estos cambios infieren en un comportamiento ascendente, a medida que el dispositivo opera en el rango de temperatura de unión se presenta como un mecanismo de radiación y convección de calor, estos cambios térmicos son representados por una distribución al azar en los patrones de speckle y poniendo a la metrología óptica como una alternativa para determinar el funcionamiento del dispositivo electrónico de estudio.
\end{abstract}

Patrón de speckle, Función de densidad de probabilidad, Regulador de tensión

Citation: LÓPEZ-ÁLVAREZ, Yadira Fabiola, JARA-RUÍZ, Ricardo, RODRÍGUEZ-FRANCO, Martín Eduardo, and DELGADO-GUERRERO, Sergio Humberto. Analysis of speckle patterns in electronic devices for the monitoring of current changes. ECORFAN Journal-Taiwan. 2021. 5-9: 1-7

\footnotetext{
* Author correspondence (e-mail: yadira.lopez@utna.edu.mx)

$\dagger$ Researcher contributing as first author.
} 


\section{Introduction}

Recent studies have allowed the development of new and improved electronic devices that perform various tasks (Park, 2012), such is the case of the positive voltage regulator; Among its applications, the regulation of fixed voltages can be mentioned, they are also used as external components to obtain adjustable voltages and currents and as a power pass-through element, among others (Rashid, 2006). However, the passage of current through electronic devices can generate heat between their terminals and in the device itself, affecting its performance or causing structural damage (López, 2018).

Various works on the measurement of operation, temperature and structural changes of electronic devices have been developed, using both destructive and non-destructive tests (López, 2018), (Ashrafi, 2019) and (Avenas, 2012), considering that in an electronic system connected to a power source, most of its components generate heat. Ahmed et.al, in a study carried out to determine the effects of overheating in electronic devices determined that these are the product of the physical and chemical properties of the device, highlighting the study in silicon wafers where the concentration of electrons directly affect the phonons, preventing heat dissipation, however, surface fractures occur in the device due to fatigue of the semiconductor material, they also mention causes such as welding of the components, among others (Ahmed, 2017).

The main purpose of voltage regulators is to maintain inputs and outputs with stable parameters under variable input and load conditions (Schuler, 1986), being one of the most used IC integrated circuits (Rashid, 2006), they provide output currents of Around the milliampers, they have a protection circuit, its main purpose being to limit the current, it is inactive when the device works under normal operating conditions and it is activated when it is working at the limit (Cirovic, 1991).

Several are the parameters that are considered for the analysis of the operation of the ICs, among which the maximum dissipation power, quiescent current, voltage drops, among others can be highlighted. However, changes in these parameters can influence the operation of ICs, according to the datasheets (Whitaker, 2005).
For these reasons, the study of the structural behavior of electronic devices, through the use of optical metrology, in addition to providing information on the operation of the device, encourages the implementation of nondestructive techniques. The purpose of this work is to study the structural changes in electronic devices in operation, subjected to current changes, without bringing the structure of the analyzed device to a breaking point.

\section{Power in electronic devices}

The power dissipated by the electronic device is released in the form of heat, considered one of the most important factors in the loss of stability of the systems (Avenas, 2012), (Boylestad, 2003), it is represented by the equation (1).

$P_{d}=f_{s} \int_{0}^{1 / f_{s}} v(t) I(t) d t$

Where $f_{s}$ represents the frequency, $1 / f_{s}$ is a cycle period of the signal, $v(t)$ and $I(t)$, are the voltage and the current. If it is instantaneous power, equation (1) will be given as the product of voltage and current, equation (2).

$P_{d}=v * I$

Since the dissipation power influences the temperature and thermal resistance of the device, the following relationship can be made (Donate, 2010), (Whitaker, 2005):

$T_{j}=T_{A}+P_{d} \theta_{J A}$

Where $T_{j}$ is the junction temperature in degrees Centigrade $\left({ }^{\circ} \mathrm{C}\right), \mathrm{T}_{\mathrm{A}}$ represents the ambient temperature in the vicinity of the device housing, $\mathrm{P}_{\mathrm{D}}$ the power dissipated by the device in Watts (W) and $\theta_{\mathrm{JA}}$ represents the thermal resistance bonding to the environment, this can also be determined by adding the thermal resistances that comprise the different parts of the device, equation (4).

$$
\theta_{J A}=\theta_{J C}+\theta_{C S}+\theta_{S A}
$$

Where $\theta_{\mathrm{JC}}$ is the thermal resistance of the junction to the case, $\theta_{\mathrm{CS}}$ is the thermal resistance of the case to the heatsink and, $\theta_{\mathrm{SA}}$ the thermal resistance of the case to the environment, each of these parameters are described in the datasheet, with units of degrees centigrade / watts $\left({ }^{\circ} \mathrm{C} / \mathrm{W}\right)$ (Whitaker, 2005). 
Therefore, from equation (3), the power dissipated can be represented as a function of the difference in the junction $T_{j}$, the environment $T_{A}$ and the thermal resistance of the junction to the environment, where the latter depends on the resistances between the junction and the casing, the heatsink and the environment, as indicated in equation (4).

$P_{D}=\frac{T_{j}-T_{A}}{\theta_{J A}}$

Where $\theta_{\mathrm{JA}}$ is the thermal resistance, for values of conduction mechanisms this is considered constant and is described in terms of the length, area of the section and thermal conductivity, however, for cases of radiation and convection it will depend on the thermal changes and will be validated only for small changes according to equation (4). In terms of thermal resistance, equation (5) can be rewritten as:

$$
P_{D}=\frac{T_{j}-T_{A}}{\theta_{J A}}=v * I
$$

The analysis of the current behavior in the device is shown in equation (7).

$I=\frac{T_{j}-T_{A}}{\theta_{J A} * v}$

According to the above, it is feasible to perform an analysis of the behavior of the IC through current changes represented as a thermal mechanism, as shown by equation (7).

\section{Origin of the speckle pattern}

From the different destructive techniques that take each analyzed device to the maximum working range, the need arises to estimate the operating variables that interfere with its behavior, using non-destructive analyzes, in which optical metrology can stand out (López, 2018). There are several techniques that involve a beam of light as a measurement system, however, the analysis of the structural characteristics of the elements can be studied using DSP (Digital Speckle Patter), this technique consists of the measurement of full optical field and It is used to determine the deformations of the object that is illuminated by a laser beam by means of the mottling movements (speckle);
The results obtained can be seen as two images with a slight change in the study points $(\mathrm{x}, \mathrm{y})$; uses the correlation between these two images to find the average displacement of the study surface, see Figure 1 (Stetson, 2011, Sirohi, 1993).

Optical metrology techniques base their measurement on a laser light system with temporal and spatial coherence characteristics, this is made to impinge on an optically rough surface, presenting a random intensity distribution, giving rise to the phenomenon called speckle ( Rastogi, 2001); said phenomenon is a representation of bright and dark points formed by the random distribution of said coherent light, the intensity of a speckle field at a point in space $P$ is determined by the coherent sum of the contributions of the complex amplitudes, considering that the study surface is rough compared to the wavelength. At the microscopic level, a surface will show a random distribution of the amplitude contributions of the phase differences at an observation point $\mathrm{P}$. As a consequence of this, the coherent sum of each of the dark and bright amplitudes will depend on how many phases come to pass through point $\mathrm{P}$ (Rastogi, 2001).

In general, the statistical properties of the speckle pattern depend on the coherence of the incident light and the surface of the medium (Rastogi, 2001), (Dainty, 1975), (Dainty, 1977). If each wave has coherence characteristics and can be represented in turn by a phasor, then it is possible to represent the resulting field as the sum of the phasor. The real and imaginary components of said resulting phasor can be expressed according to equations (8), (9), within the interval $(-\pi, \pi)$, where $\mathrm{N}$ represents the number of phasor, $\mathrm{A}$ is the resulting phasor of amplitude, the phase $\emptyset_{\mathrm{k}}$ and $\mathrm{a}_{\mathrm{k}}$ represents the nth phasor (Rastogi, 2001), (Dainty, 1977):

$$
\begin{aligned}
& \mathrm{R}=\operatorname{Re}\{A\}=\frac{1}{\sqrt{N}} \sum_{k=1}^{N}\left|a_{k}\right| \cos \emptyset_{k} \\
& \mathrm{I}=\operatorname{Im}\{A\}=\frac{1}{\sqrt{N}} \sum_{k=1}^{N}\left|a_{k}\right| \operatorname{sen} \emptyset_{k}
\end{aligned}
$$

These speckle patterns take coherence as a constant of intensity (Dainty, 1977); In some measurements it is very common to see only calculations of the intensity of the optical wave field, through a transformation of the random variable equation (Rastogi, 2001), (Dainty, 1975), (Dainty, 1977). 
Where the probability density function of the intensity I and the phase $\square$ of a developed speckle is given by equations (10) and (11), (Nolte, 2012).

$$
\begin{aligned}
& P_{I}(I)=\frac{I}{\langle I\rangle} \exp \left(-\frac{I}{\langle I\rangle}\right) \\
& P_{\varnothing}(I)=\frac{I}{2 \pi} \quad \emptyset \in[0,2 \pi]
\end{aligned}
$$

For the case of the analysis of the speckle pattern, the second order statistic implies the autocorrelation function of the intensity distribution and the power spectral density, defining the first as:

$$
\begin{aligned}
& R_{1}=\left(x_{1}, y_{1}, ; x_{2}, y_{2},\right)=\left\langle I\left(x_{1}, y_{1}\right) I\left(x_{2}, y_{2}\right)\right\rangle= \\
& \left\langle\left|A\left(x_{1}, y_{1}\right)\right|^{2}\left|A\left(x_{2}, y_{2}\right)\right|^{2}\right\rangle
\end{aligned}
$$

Where A represents the complex field, the width of this function is known as the central lobe and gives an approximation to the measurement of the average diameter of the speckle size, if the surface presents roughness compared to the wavelength, the field is a variable complex circular at each point of $(x, y)$ and the intensity autocorrelation function will then be represented as:

$$
\begin{aligned}
& \mathrm{R}_{1}=\left(\mathrm{x}_{1}, \mathrm{y}_{1}, ; \mathrm{x}_{2}, \mathrm{y}_{2}\right)=\left\langle\mathrm{I}\left(\mathrm{x}_{1}, \mathrm{y}_{1}\right) \mathrm{I}\left(\mathrm{x}_{2}, \mathrm{y}_{2}\right)\right\rangle+ \\
& \left|\mathrm{J}_{\mathrm{A}} \mathrm{x}_{1}, \mathrm{y}_{1}, ; \mathrm{x}_{2}, \mathrm{y}_{2}\right|^{2}
\end{aligned}
$$

Where:

$$
J_{A}\left(x_{1}, y_{1}, ; x_{2}, y_{2}\right)=\left\langle A\left(x_{1}, y_{1}\right) A^{*}\left(x_{2}, y_{2}\right)\right\rangle
$$

According to Goldfisher, it is feasible to perform a second-order statistical analysis of the speckle patterns based on their autocorrelation function, their Fourier transform and the spectral power density (Henao, 1997), (Somkuwar, 2017), (Sharma, 2006 ). Both the probability density and the autocorrelation function are cataloged as the principle of the correlation techniques of the speckle patterns, for the case of the processing of the images resulting from the speckle pattern, two states of deformation of the study surface are considered.

\section{Development}

For the test circuit, a positive voltage regulator (LM7805) was used, type of TO-200 encapsulation, a power source with 8 input volts, the current was controlled from 50 to 500 milliampers (mA), a resistance was placed load of $100 \Omega$ at the output of the electronic device,

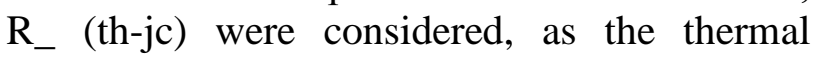
resistance of junction to the case $3^{\circ} \mathrm{C} / \mathrm{W}, \mathrm{R}$ (th-ja) thermal resistance to the environment 50 ○ C / W (Bakshi, 2009). Equation (2) was used, taking $\mathrm{V}$ as a voltage difference between the supply of the test circuit and the output voltage of the device, $\mathrm{I}$ is considered as the input current that is controlled and a stable ambient temperature of $25^{\circ} \mathrm{C}$.

To obtain the speckle patterns, a 632.8 nm He-Ne laser light source was used, a CCD camera to obtain the patterns and a computer for data processing, Figure 1 (Sirohi, 1993).

The deformation of the system was induced by current changes and the behavior of each terminal of the device was analyzed: input (Input (1)), ground (ground (2)) and output (output (3)), before and after the current changes.

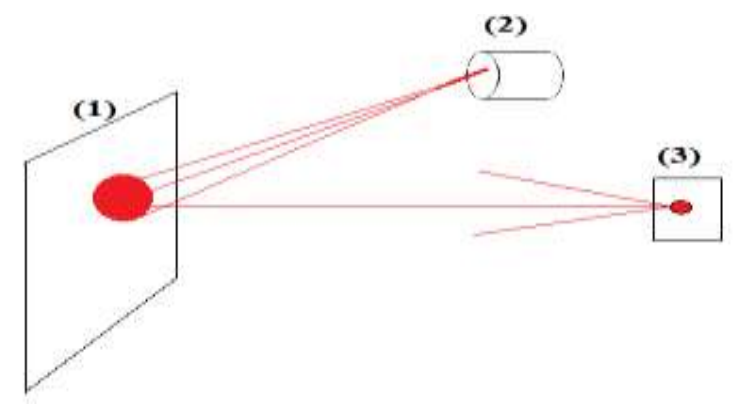

Figure 1 Optical system to obtain speckle patterns (1) Object, (2) Laser, (3) Observation plane, (Sirohi, 1993)

The normalized probability density function and the behavior of the correlation coefficients with different input current values were calculated.

The probability density function of the speckle patterns of each terminal of the device with different current values and a comparison between the correlation coefficients with changes in junction temperature was obtained.. 


\section{Results}

Since the main purpose of this work is the analysis of the operation of electronic devices for control and monitoring of technical specifications, as well as lengthening their life time, the statistical behavior of the speckle patterns of each of the terminals of the electronic device, input, output and ground.

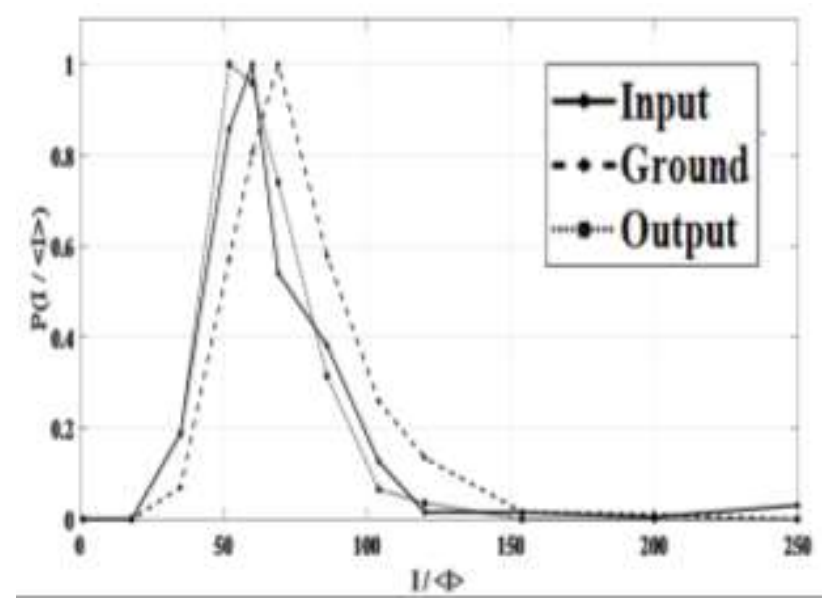

Graph 1 Probability density function of the speckle patterns obtained from the device without device power supply terminals (Input, Output and Ground)

Source: Own Elaboration

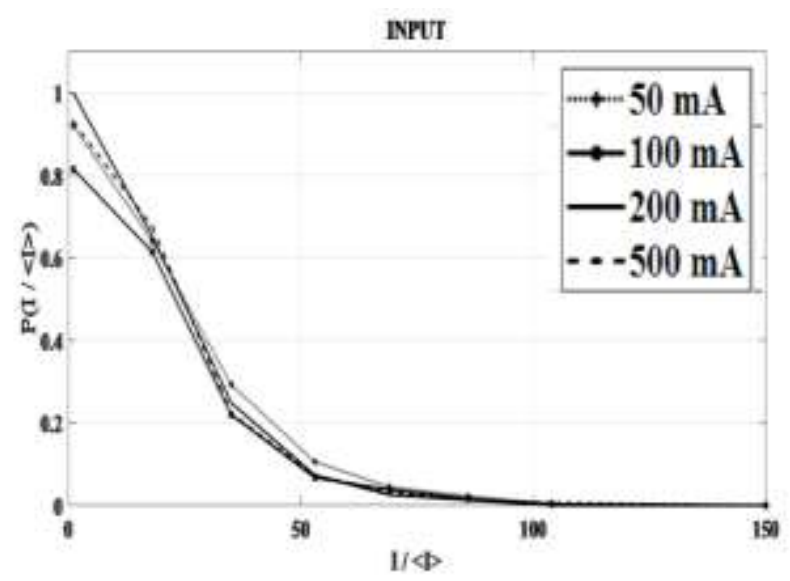

Graph 2 Probability density function of speckle patterns: Device input terminal

Source: Own Elaboration

Graph 1 shows the behavior of the probability density function originating from the speckle pattern resulting from irradiating the device with coherent light, these results are taken as a reference for the analysis of the speckle patterns, it can be seen that for the terminals of the device, the negative exponential shape is preserved, as the supply current of the device increases, the maximum points of the density function show a non-linear behavior, suggesting that this resulting speckle pattern corresponds to a low-contrast speckle pattern. 3, 4 and 5.

\begin{tabular}{|r|r|r|r|r|}
\hline \multicolumn{1}{|c}{$\boldsymbol{m} \boldsymbol{A}$} & \multicolumn{1}{c}{$\boldsymbol{~}{ }^{\circ} \boldsymbol{C}$} & \multicolumn{1}{c|}{$\boldsymbol{T}_{\boldsymbol{j}}$} & $\boldsymbol{R}_{\mathbf{1}}$ \\
\hline 50 & 0.15 & 7.5 & 32.5 & 0.20205 \\
\hline 100 & 0.30 & 15 & 40 & 0.20635 \\
\hline 200 & 0.60 & 30 & 50 & 0.21555 \\
\hline 500 & 1.5 & 75 & 100 & 0.25085 \\
\hline
\end{tabular}

Table 1 Thermal and electrical characteristics and correlation coefficients of the electronic device Source: Own Elaboration



Graph 3 Probability density function of speckle patterns: Device output terminal Source: Own Elaboration

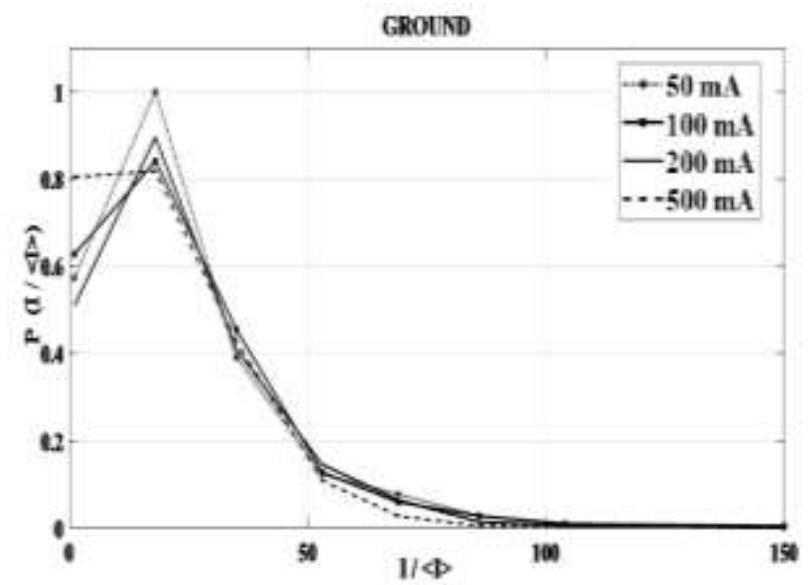

Graph 4 Probability density function of speckle patterns: Device ground terminal Source: Own Elaboration

For this study, the behavior of the average of the correlation coefficients resulting from the increase in the current is also analyzed, presenting in a similar way and in an ascending way, as shown in Table 1 . The averages of the correlation coefficients were obtained from Considering all the sections of the electronic device, it can be seen that from $50^{\circ} \mathrm{C}$ (degrees centigrade), in the temperature range of the joint in operation, the value of the average coefficient increases significantly compared to the values for lower temperature, allowing an approximation between the statistical characteristics of the speckle patterns and the thermal properties of the device and that are the product of current changes at the input of the electronic device.

LÓPEZ-ÁLVAREZ, Yadira Fabiola, JARA-RUÍZ, Ricardo, RODRÍGUEZ-FRANCO, Martín Eduardo, and DELGADOGUERRERO, Sergio Humberto. Analysis of speckle patterns in electronic devices for the monitoring of current changes. ECORFAN Journal-Taiwan. 2021 

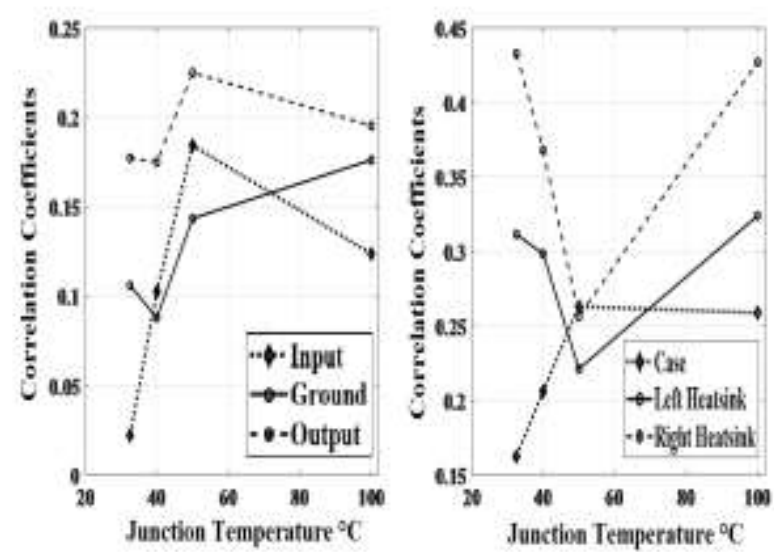

Graph 5 Behavior of correlation coefficients of the device and the junction temperature

Source: Own Elaboration

Graph 5 shows the behavior of the correlation coefficients obtained by means of second order statistics, also, a change in their behavior is observed around $50^{\circ} \mathrm{C}$ of junction temperature of the device, these changes are present in all parts of the device analyzed, which suggests that the DSP technique can monitor and correlate changes in the junction-ambient temperature of the device, registering as similar points in behavior.

Also, second order statistics were applied to the case and heatsink of the device, left and right side (left heatsink and rigth heatsink), Graph 5; It can be seen that the correlation coefficient located at $50{ }^{\circ} \mathrm{C}$ of the junction temperature for the case of the case and the right side of the heatsink (near the output terminal) are very similar with a difference of 0.00663 arbitrary units ( ua), relating the behavior of the probability density function for this section of the dissipator since it presents greater broadening than its counterpart.

On the other hand, the value of the coefficients for the case of each terminal, it can be seen that these do not exceed the value of 0.25 (u.a.), turning out to be very similar to that presented by the housing and the right section of the device.

\section{Conclusion}

The theoretical probability density function that illustrates the statistical behavior of speckle patterns can be demonstrated experimentally.
The changes of this function were obtained for current values between the working range of a voltage regulating device, allowing to determine the behavior of the electronic device by approximating its thermal characteristics with the statistical properties of the speckle pattern that originates in the surface of the same and assuming that these speckle patterns will show changes according to thermal resistance. DSP is taken as a monitoring technique in the change of internal and external thermal value that affect the operation of the device as well as anticipating future structural damage.

It was possible to demonstrate that by means of optical techniques it is feasible to determine the range in which the current supply enables the thermal point of the junction resistance considered stable, by means of a change in the behavior of the correlation coefficients. Also, the average behavior of the coefficients for each power change in the test circuit is disclosed, concluding that these present an upward behavior, similar to the increase in the input current.

\section{References}

Ahmed Almubarak Adel. Int. Journal of Engineering Research and Application, 7, (2017), pp. 52.

Avenas Y., Dupont L., Khatir Z., IEEE Trans. Power Electron, 27 (2012) pp. 3081.

Bakshi U.A., Godse A.P, Analog and Digital Electronics, 1 st ed, (Technical Publications Pune, India, 2009), Cap7 pp.13-19.

Boylestad R. L., Nashelsk L., Electrónica: Teoría de Circuitos y Dispositivos Electrónicos, 8va ed. (Pearson Educación, México, 2003), pp.335.

Cirovic M.M., Electrónica Fundamental: Dispositivos, Circuitos y Sistemas, (Reverté, Spain 1991), pp.383.

Dainty C., Progress in Optics, 14 (E. Wolf, 1977), pp. 1-46.

Dainty J.C., Laser Speckle and Related Phenomena, 1st ed, (Springer, Verlag Berlin Heidelberg, 1975), pp.1-2. 
Donate A. H., Principios de Electricidad y Electrónica III, 2nd Ed., (Marcombo, 2010) pp.309.

Henao R.J.H., Estudio de Técnicas Speckle Opto-Digitales, CIO, 1997.

López Y. F., Casillas F. J., Peña F. G., Muñoz J., Rodríguez M. E. and Orozco S. M., 15th International Conference on Electrical Engineering, Computing Science and Automatic Control (CCE), (2018) pp.1-5.

Mahdi Ashrafi, Component Heating Sub Systems and Methods for Laser Shearography Testing Systems, US 10,837,761 B1, Filed: Apr. 30, 2019, issued Nov. 17, 2020.

Nolte D. D., Optical Interferometry for Biology and Medicine, 1st Ed, (Springer, NY Dordercht Heidelberg London, 2012), pp106-110.

Park J.S., Maeng W. J., Kim H.S. and Park J.S., Thin Solid Films. 520 (2012) pp. 1679.

Rashid M. H., Power Electronics Handbook: Devices, Circuit and applications, second ed. (Elsevier, USA, 2006), pp. 598-612.

Rastogi P.K., Digital Speckle Pattern Interferometry and Related Techniques, $1 \mathrm{st} \mathrm{Ed}$, (Wiley, 2001), pp. 289-321.

Schuler C. A., Electrónica: Principios y Aplicaciones, (Reverté, Spain, 1986), pp.55.

Sharma K. K., Optics: Principles and Applications, 1st Ed, (Elsevier, USA, 2006) pp. 402-407.

Sirohi R. S., Speckle Metrology, 38 va ed. (Marcel Deccker Inc. NY, 1993), pp.3.

Somkuwar A. S., Das B., Vinu R. V., Park Y., and Singh R. K., J. Opt. Soc. Am. A-Opt. Image Sci.Vis. 34 (2017) pp. 1392.

Stetson Karl Associates, LLC, optical measurement, modeling and metrology, vol. 5, Analysis of speckle photographs by subtracting phase functions of digital Fourier transforms, (2011) pp. 199-207.

Whitaker J. C., The Electronics Handbook, (Taylor\& Francis Group, Broken Sound Parkway NW, 2005), pp. 1041. 